\title{
Seroprevalence of hepatitis B, hepatitis C and HIV 1 / 2 in patients undergoing surgery in a tertiary care hospital in north India (a hospital based study)
}

\author{
Nahid Nahvi ${ }^{\mathrm{a}, *}$, Sanah Farooq ${ }^{\mathrm{b}}$ \\ ${ }^{a}$ Department of Microbiology, Government Medical College and Associated Hospitals, Srinagar, Jammu and Kashmir, 190010, India \\ ${ }^{\mathrm{b}}$ Department of Biochemistry, Government Medical College and Associated Hospitals, Srinagar, Jammu and Kashmir, 190010, India
}

\section{A R T I C L E I N F O}

\section{Keywords:}

Hepatitis B virus

Hepatitis C virus

Human immunodeficiency virus

Enzyme linked immunosorbent assay (ELISA)

Rapid test

\begin{abstract}
A B S T R A C T
This was a prospective observational study carried over a period of one year (1st Jan - 31st Dec 2018). The aim of the study was screening of Hepatitis B, Hepatitis C and HIV infection in patients undergoing elective surgery in order to provide both preventive and treatment services and to reduce the transmission to health care workers. Materials and methods: The patients dated for elective surgery were taken up for the study. These patients were screened for $\mathrm{HBs} \mathrm{Ag}$ and antibodies to hepatitis C and HIV 1/2 respectively. SD HBs Ag ELISA 3.0 and SD HCV ELISA 3.0 were used for detection of HBs Ag and IgG antibodies to HCV respectively. The antibodies to HIV $1 / 2$ were identified by coomb AID, a rapid immunoassay test.

Results: In our study we have found that the prevalence of HBV and HCV infection was $1.91 \%$ and $1.05 \%$ respectively. Three patients were positive for both HBV and HCV $(0.03 \%)$ None of the patients were positive for HIV.

Conclusion: There is a significant seroprevalence of hepatitis B and hepatitis C viral infections in surgical patients. Risk factors include reuse of contaminated syringes, surgical instruments and lack of pre/postoperative precautions.
\end{abstract}

\section{Introduction}

HBV, HCV and HIV are three important viral infections which share common modes of transmission, the most important being the transmission via contaminated blood and blood products. ${ }^{1}$ Transmission also occurs by inoculation during surgical or dental procedure. ${ }^{2}$ Chances of transmission of HBV, HCV and HIV following a contaminated needle stick injury are nearly $30 \%, 3 \%$ and $0.3 \%$ respectively. ${ }^{3}$ The other modes of transmission include sexual contact especially in homosexual males and vertical transmission from infected mother to fetus. High risk groups who are more prone to get infection are surgeons, paramedical workers, sex workers, patients on dialysis, hemophiliacs, drug addicts, patients who receive repeated blood transfusions and patients with solid organ transplantation. ${ }^{4-7}$ HBV and HCV infections are two important causes of chronic hepatitis, cirrhosis and hepatocellular carcinoma. Worldwide more than 500 million people suffer from chronic hepatitis. $^{3}$

HBV is a double stranded DNA virus belonging to genus orthohepadnavirus and family hepadnaviridae with 10 genotypes. ${ }^{8}$ Worldwide
257 million people are chronically infected with HBV. One million deaths result from complications of chronic HBV infection, that is, cirrhosis and hepatocellular carcinoma. Prevalence in Asia is estimated to be greater than $10 \%$ resulting primarily from perinatal transmission after which the likelihood of acquiring chronic infection is $90 \%$. In adults the infection resolves in more than $95 \%$ of otherwise healthy people. ${ }^{9}$ Detection of HBs Ag is the most important and reliable test for diagnosing HBV infection. It is the first marker to be elevated and appears usually between 8 and 12 weeks and about 2-6 weeks before the biochemical and clinical evidence of hepatitis. The antigen is usually cleared within 1-2 months. Persistence beyond 6 months suggests progression to chronic hepatitis and a carrier state. ${ }^{8}$ Hepatitis B core antigen $(\mathrm{HBc} \mathrm{Ag}$ ) is surrounded by $\mathrm{HBs} \mathrm{Ag}$ and is non secretory, therefore it is not detected in the blood. Antibody to $\mathrm{HBc} \mathrm{Ag}(\mathrm{IgM})$ is the first antibody to be elevated after infection and appears 1-2 weeks after the appearance of $\mathrm{HBs} \mathrm{Ag}$ and lasts for 3-6 months. ${ }^{10}$ Its presence indicates acute hepatitis B infection. HBe Ag and HBV DNA appear concurrently with or shortly after the appearance of $\mathrm{HBs} \mathrm{Ag}$ in serum and are the markers of active viral replication suggesting high viral

\footnotetext{
* Corresponding author. Department of Microbiology, Government Medical College, Srinagar, India.

E-mail address: drnahidnahvi@gmail.com (N. Nahvi).
} 
infectivity (that is high transmission rate). Presence of $\mathrm{HBs} \mathrm{Ag}$ may be the only marker during the early incubation period. Appearance of antibody to $\mathrm{HBs} \mathrm{Ag}$ (after infection) suggests recovery from infection and non-infectivity and it persists then indefinitely. ${ }^{8}$

HCV is a single stranded RNA virus belonging to genus hepacivirus and family flaviviridae. There are currently six genotypes (1-6) and HCV exists as a quasi-species because of its high mutation rates. ${ }^{8}$ Most common modes of transmission include exposure to small quantities of blood during injection drug abuse, unsafe injection practices and use of unscreened blood and blood products. Worldwide 71 million patients have chronic HCV infection and are at risk of developing cirrhosis and hepatocellular carcinoma. Approximately 399000 people die of HCV. About $30 \%$ of patients infected with HCV may clear the infection due to a strong immune response. ${ }^{10}$ HCV RNA can be detected in days after exposure and remains the gold standard for the diagnosis of HCV infection. Viremia peaks in 8-12 weeks after infection plateaus and then drops to lower level. Persistence of infection is seen in $85-90 \%$ of the individuals. The major consequence of HCV infection is hepatic fibrosis which may progress to life threatening cirrhosis and an increased risk of hepatocellular carcinoma. Anti HCV antibodies appear in 8-9 weeks after exposure and are detectable in more than $95 \%$ of chronic cases however in acute hepatitis antibodies are variably present detectable in $50-70 \%$ patients. Detection of HCV RNA remains the gold standard for the diagnosis of hepatitis $\mathrm{C}$. Therefore patients showing presence of Anti HCV should be confirmed by nucleic acid amplification. ${ }^{11} \mathrm{HBV}$ and $\mathrm{HCV}$ co infection has been reported in high risk patients screened before surgery. In one of the studies in HIV patients $28.4 \%$ were positive for HBS Ag and $14.7 \%$ for anti-HCV. ${ }^{12}$

Human Immunodeficiency virus (HIV), the causative agent of Acquired Immunodeficiency syndrome (AIDS) is a RNA virus belonging to the family retroviridae and genus lentivirus. Currently two viruses HIV-1 and HIV-2 have been identified. The majority of the infections are associated with HIV-1. Retroviruses possess a unique enzyme called reverse transcriptase that directs the synthesis of DNA from viral RNA after they infect a host cell. The virus is transmitted primarily by heterosexual route $(75 \%$ of total cases). Other modes of transmission include infected blood, percutaneous, mucosal and perinatal modes. Viral load is maximum in blood, genital secretions, cerebrospinal fluid and breast milk. The laboratory test for HIV include screening tests for antibody detection, Rapid tests (takes $<30 \mathrm{~min}$ ) and ELISA (takes $2-3 \mathrm{~h}){ }^{3,8}$ As per NACO (National AIDS control organization) guidelines three screening tests based on different principles or antigens are done. The first test has to have high sensitivity and if the first test is positive it is to be confirmed by second and third which have high specificity.

\section{Materials and methods}

This was a prospective observational study. The patients who were dated for elective surgery in the departments of General Surgery, Ophthalmology and ENT were taken up for the study. The study was done for a period of one year with effect from 1st Jan 2018 to 31st December 2018. A total of 9252 patients were screened for HBs Ag and antibodies for HCV and HIV. SD HBs Ag ELISA 3.0 and SD HCV ELISA 3.0 were used for the detection of HBs Ag and antibodies to HCV. Rapid test with a high sensitivity as per NACO guidelines was used for identification of antibodies to HIV 1 and 2.

\subsection{Collection and storage}

Under all proper aseptic precautions whole blood was collected by venipuncture, centrifuged to get serum specimen. The specimens were then refrigerated as the tests were done on two specific days each week.

\subsection{ELISA for hepatitis B surface antigen (HBsAg)}

SD HBs Ag ELISA 3.0 is a double sandwich ELISA for qualitative detection of HBs Ag in human serum or plasma. The microplate is precoated with anti-hepatitis B virus surface antigen (anti HBs). During first incubation patient's serum as well as conjugate is added one after the other. HBs Ag if present in patient's serum binds to Anti HBs on the well. Enzyme conjugate which contains Anti HBs conjugated to horse radish peroxidase (HRPO) is also added. The HBs Ag will also bind the Anti HBs in conjugate thus forming a sandwich. Following this incubation all the unbound material was removed by aspiration and washing. The residual enzyme activity in the well is directly proportional to HBs Ag concentration in patient's serum and evidenced by incubating the solid phase with a substrate solution (TMB) in a substrate buffer. $1.6 \mathrm{~N}$ sulfuric acid is used as a stopping solution. With each run three negative and two positive controls were put. With each run colorimetric reading was performed by using spectrophotometer at $450 \mathrm{~nm}$. Interpretation of results: Mean absorbance of negative control was calculated. Then cut off value was calculated by adding 0.050 to mean absorbance of negative controls (as per the kit insert).

$$
\begin{aligned}
& \mathrm{A}(\text { neg })+0.050=\text { cut off value } \\
& \text { Sample }<\text { cut off }- \text { HBs Ag negative } \\
& \text { Sample }>/=\text { cut off }- \text { HBs Ag positive }
\end{aligned}
$$

The positive serum samples were also tested by Rapid tests to confirm their efficacy (Fig. 1 and Fig. 4).

\subsection{ELISA for anti $\mathrm{HCV}$}

SD HCV ELISA 3.0 is an indirect sandwich ELISA for the qualitative detection of antibodies against HCV. Here the microplate is pre coated with recombinant HCV antigens (core, NS3, NS4, NS5). During first incubation anti HCV in patient's serum is bound to recombinant HCV antigens. Following this the unbound materials are removed by aspiration and washing. The enzyme conjugate containing goat antihuman IgG conjugated to horse radish peroxidase (HRPO) binds to anti HCV. The residual enzyme activity found in the wells is directly proportional to anti HCV concentration in the patient's serum and evidenced by incubating the solid phase with substrate solution (TMB). In a substrate solution $1.0 \mathrm{~N}$ sulfuric acid is used as a stopping solution. With each run we put three negative and two positive control wells. Interpretation of results: The mean absorbance of negative wells is calculated and to that we add 0.400 . This gives us the cut off (as per the kit insert).

Samples < cut off - negative for anti-HCV

Samples $>/=$ cut off - positive for anti-HCV

The positive samples were tested in duplicates. Also Rapid tests for HCV were done for positive specimens in order to analyze the efficacy of Rapid tests (Fig. 2 and Fig. 3).

\section{Results and discussion}

A total of 9252 patients were screened for the three viral infections.

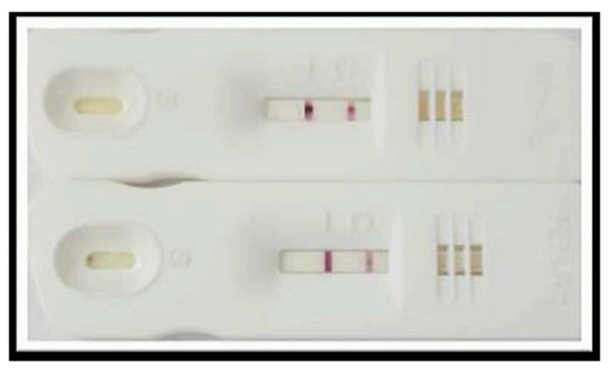

Fig. 1. ICT showing test positive for HBsAg. 


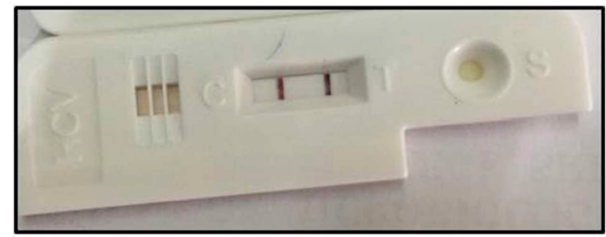

Fig. 2. ICT showing test positive for HCV.

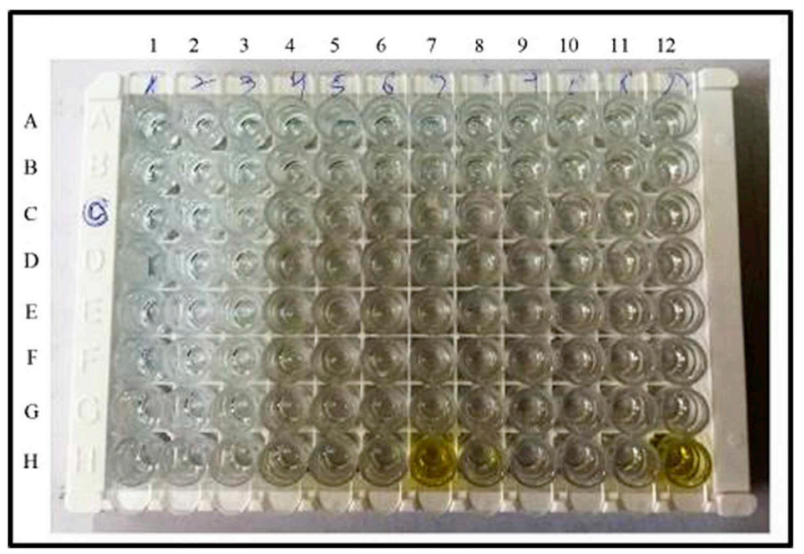

Fig. 3. ELISA for $\mathrm{HCV}$; $7 \mathrm{H}$ positive sample, $12 \mathrm{H}$ positive control.

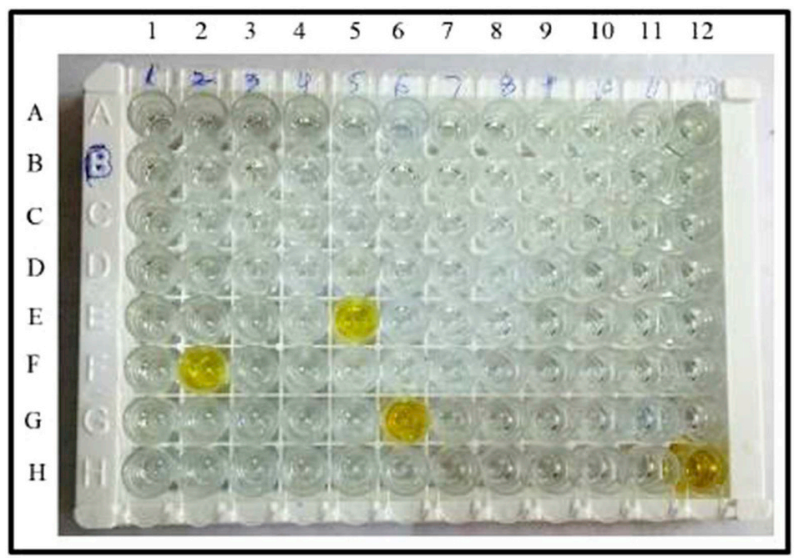

Fig. 4. ELISA for HBV; 2F, 5E, $6 \mathrm{G}$ positive for $\mathrm{HBsAg}, 12 \mathrm{H}$ positive control.

Table 1

Prevalence of Hepatitis B, Hepatitis C and HIV.

\begin{tabular}{lllll}
\hline Infections & $\begin{array}{l}\text { Males } \\
(\mathrm{n}=4901)\end{array}$ & $\begin{array}{l}\text { Females } \\
(\mathrm{n}=4351)\end{array}$ & $\begin{array}{l}\text { Total } \\
(\mathrm{n}=9252)\end{array}$ & $\%$ \\
\hline HBV & 114 & 60 & 174 & 1.88 \\
HCV & 50 & 48 & 98 & 1.05 \\
$\begin{array}{l}\text { Co-infection (HBV } \\
\text { and HCV) }\end{array}$ & 3 & - & 3 & 0.03 \\
HIV & - & - & - & - \\
Total & 167 & 108 & 275 & 2.97 \\
\hline
\end{tabular}

Among them 4901 (52.97\%) were males and 4351 (47.02\%) were females. A total of 174 patients were positive for $\mathrm{HBs} \mathrm{Ag}, 98$ patients were positive for HCV and 3 male patients were positive for both HBs $\mathrm{Ag}$ and HCV co-infection. None of the patients were positive for HIV 1/ 2 (Table 1).

A total of $1.88 \%$ patients were positive for $\mathrm{HBs} \mathrm{Ag}$ with a higher prevalence among males $114(1.23 \%)$ as compared to females 60 $(0.64 \%)$. A total of $1.02 \%$ patients have shown positive results for anti HCV. The prevalence of HCV was much lower than HBV in our study.
There was a slightly higher prevalence of hepatitis $\mathrm{C}$ infection among males $(0.54 \%)$ as compared to females $(0.51 \%)$ (Table 1$)$.

Only three patients showed positive results for both hepatitis B and hepatitis C co-infection. Two of these patients were hemophiliacs and one patient was diagnosed rectal carcinoma and was positive for HBs $\mathrm{Ag}$ and HCV after he had received chemotherapy. Co infection of HBV and HCV has been documented in immunocompromised patients putting them at an increased risk of developing CLD, cirrhosis and hepatocellular carcinoma. ${ }^{13,14}$ None of the patients were positive for HIV 1/ 2. All the samples tested ELISA positive for HBs Ag and HCV were also positive by immuno-chromatographic test (Rapid Method) (Figs. 1 and 2). Thus rapid tests are equally good with high specificity and can be used when results are needed immediately especially in patients with pellet injuries. They are simple, rapid, need no equipment or laboratory set up. Our study was comparable to similar studies conducted in other parts of the world. A study conducted in New York on seroprevalence of HCV, HIV and HBV in surgical patients has shown the prevalence of anti HCV (5.2\%), HIV (1.6\%) and HBV (1.4\%). The prevalence of HCV $5.2 \%$ was much higher than HIV- $1.6 \%$ and HBV $1.4 \% \mathrm{P}<0.001 .{ }^{15} \mathrm{~A}$ similar study conducted on neurosurgical patients has reported a prevalence of HBV and HCV $1.88 \%$ and $1.02 \%$ respectively. No patient was positive for HIV infection. ${ }^{12}$ A research study done in north India on pre-operative patients has shown prevalence of HBV, HCV and HIV $2.09 \%, 1.77 \%$ and $0.25 \%$ respectively. ${ }^{16}$

\section{Conclusion}

Routine pre-operative screening has been recommended for HBV and HCV. The main idea behind the screening for hepatitis B, hepatitis $\mathrm{C}$ and HIV is not just infection prevention but also case detection of these three important blood borne infections. Testing and diagnosis of hepatitis B, hepatitis C and HIV is not just infection prevention but also case detection of these three important blood borne infections. Testing and diagnosis of Hepatitis B and Hepatitis C infection is the gateway to access both prevention and treatment services. Early identification of patients with chronic hepatitis B or hepatitis C infection enables them to receive the necessary care and treatment to prevent or delay progression of liver disease. Testing also provides an opportunity to reduce transmission to health care workers and provision of prevention commodities such as sterile syringes and surgical equipment. Hepatitis B is an important occupational hazard for health care workers. All the health care workers and persons at risk should receive Hepatitis B vaccine which is very safe and effective and the antibody titer needs to be monitored so that booster dose is given when antibody titer falls below $10 \mathrm{IU} / \mathrm{ml}$. We therefore recommend screening for hepatitis B and C infection for all patients who are undergoing surgical procedures. Further advocating early antiviral medicines can cure $>95 \%$ people with hepatitis $\mathrm{C}$ infection thereby reducing the risk of death due to cirrhosis and hepatocellular carcinoma.

\section{Acknowledgements}

This work was supported by the Department of Microbiology, Government Medical College Srinagar. There is no conflict of interests among the authors.

\section{Appendix A. Supplementary data}

Supplementary data to this article can be found online at https:// doi.org/10.1016/j.cegh.2019.04.004.

\section{References}

1. Goldman DA. Blood borne pathogens and nosocomial infection. J Allergy Clin Immunol. 2002;110(2 Suppl):S21-S26 Aug.

2. Laheij AMGA, Kistler JO, Belibasakis GN, Välimaa H, De Soet JJ. European Oral 
Microbiology Workshop (EOMW) 2011. Healthcare associated viral and bacterial infections in dentistry. J Oral Microbiol. 2012;4. https://doi.org/10.3402/jom.v4i0. 17659.

3. Jawetz, Melnick, Adelberg's. Medical Microbiology 26th edition, Chap. 35, P 52-53.

4. Maheshwari A, Ray S, Thuluvath PJ. Acute hepatitis C. Lancet. 2008 Jul 26;372(9635):321-332.

5. Bernieh B. Viral hepatitis in haemodialysis: an update. J Transl Int Med. 2015 JunSep;3(3):93-105.

6. Tang S, Lai KN. Chronic viral hepatitis in hemodialysis patients. Hemodial Int. 2005 Apr;9(2):169-179.

7. Mikolašević I, Sladoje-Martinović B, Orlić L, et al. Evaluation of viral hepatitis in solid organ transplantation. Acta Med Croat. 2014 Apr;68(2):151-159.

8. Bennet JE, Doli R, Blaser MJ. Principles and Practice of Infectious Diseases. eighth ed., vol 1, (chapter 119) p 1439-1448.

9. WHO Hepatitis B Fact Sheet. July 2018; July 2018.

10. WHO Global Hepatitis Report. 2018; 2018

11. Gupta E, Bajpai M, Choudhary A. Hepatitis C virus: screening, diagnosis, and interpretation of laboratory assays. Asian J Transfus Sci. 2014 Jan;8(1):19-25. https://doi.org/10.4103/0973-6247.126683.

12. Gańczak M, Szych Z. Rationale against preoperative screening for HIV in polish hospitals: a prevalence study of anti-HIV in contrast to anti-hepatitis C virus and hepatitis B surface antigen. Infect Control Hosp Epidemiol. Dec 2009;30(12)

13. Balogun TM, Emmanuel S, Ojerinde EF. HIV, Hepatitis B and Hepatitis C viruses coinfection among patients in Nigerian tertiary hospital. Pan Afr Med J. 2012;12:100.

14. Sulkowski MS. Viral hepatitis and HIV co infection. J Hepatol. 2008 Feb;48(2):353-367.

15. Montecalvo MA, Sung Lee M, DePalma H, et al. Seroprevalence of human immunodeficiency virus-1, hepatitis B virus, and hepatitis C virus in patients having major surgery. Infect central epidemol. 1995 Nov;16(11):627-632.

16. Mohan M, Sharma M, Pandey CP. Pre-operative screening of HIV, Hepatitis B and Hepatitis C - essential for surgical team and patients both. A research study in the dept. of surgery in a tertiary care institute of North India Rohikand Medical college and hospital Bareilly (UP) India. Int J Contemp Med Res. July 2018;5(7). 